\title{
Efficacy and safety of Infliximab in psoriatic patients over the age of 65
}

\section{Andrea Chiricozzi, Athanasios Pavlidis, Annunziata Dattola, Luca Bianchi, Maria Sole Chimenti, Monika Fida \& Rosita Saraceno}

To cite this article: Andrea Chiricozzi, Athanasios Pavlidis, Annunziata Dattola, Luca Bianchi, Maria Sole Chimenti, Monika Fida \& Rosita Saraceno (2016): Efficacy and safety of Infliximab in psoriatic patients over the age of 65, Expert Opinion on Drug Safety, DOI: 10.1080/14740338.2016.1226279

To link to this article: http://dx.doi.org/10.1080/14740338.2016.1226279

Accepted author version posted online: 18

Aug 2016.

Published online: 18 Aug 2016.

Submit your article to this journal $\pi$

山 Article views: 4

View related articles $\smile$

View Crossmark data $\nearrow$ 
Publisher: Taylor \& Francis

Journal: Expert Opinion on Drug Safety

DOI: $10.1080 / 14740338.2016 .1226279$

Efficacy and safety of Infliximab in psoriatic patients over the age of 65

Andrea Chiricozzi MD ${ }^{1}$, Athanasios Pavlidis $\mathrm{MD}^{2}$, Annunziata Pattola MD, ${ }^{2}$ Luca Bianchi MD ${ }^{2}$,

Maria Sole Chimenti MD³ , Monika Fida MD, Rosita Saraceno MiD?

1. Dermatology Department, University of Pisa, Pisa, Ita!y

2. Department of Dermatology University of Rome Tor Vergata - Viale Oxford 81, 00133 Rome, Italy

3. Department of Rheumatology, Allergology and Clinical Immunology University of Rome "Tor Vergata", Rome, Italy

4. Faculty of Medicine, University of Tirana, Trana, Albania

Running head: Infliximab an flderiy

\section{Corresponding Author:}

Annunziata Daitola, MD

Department of Dermatology

Policlinice Tor Vergata

Viale Oxford 8100133 Rome

Phene: - -390620902743

Fax:-390620902742

e-maail:nancydattola@gmail.com 


\section{Abstract:}

Background: clinical data on the long-term safety and efficacy of infliximab on psoriatic patients who are older than 65 years are limited.

Objectives: the aim is to report the long-term efficacy, safety and tolerance of infliximab in geriatric patients.

Methods: This was a retrospective study conducted at the Department of Dermatology of the University of Rome Tor Vergata. Clinical data were reported at week 12, 52, 104, 208.

Results: 151 charts were evaluated. A total of 27 patients were incluced. Range of the age was between 65 and 85 years; mean age was 73 years \pm 5.4 ; female to male ratio was 1:2; mean age of onset of psoriasis was 43 years \pm 17 . The average of treatinent duration was 39 months \pm 27 (range 1-100). Fourteen patients suffered from plaque type nsoriasis and 13 from psoriatic arthritis. At the baseline the mean PASI score was $15.6+10.2$. At week 12, 52, 104, and 208 the mean PASI was 2, 2.3, 1.9 and 1.8 respectively. A reduction in the mean PASI was maintained in the longterm treatment in 12 patients $(\mathrm{p}<0.001)$.

Conclusion: Our data suggest that long-term treatment with infliximab is effective and safe in patients over 65 years old and that IV therapy is also associated with a high compliance.

Key worâ. pseriasis, long-term, infliximab, elderly. 


\section{Introduction}

Psoriasis ( $\mathrm{PsO})$ is a chronic inflammatory skin disease that affects $1-3 \%$ of the worldwide population. [1] Henseler and Christophers described two clinical presentations of psoriasis, type I and II, distinguished by a bimodal age at onset. Type 1 begins on or before age of 49 vears, type II begins after the age of 40 years. [2] According with different population-based studies, 3.2$13 \%$ of patients experience psoriasis first in their lives over 60 years old, an the proportion might increase in aging society. [3-5] Moreover, it is well known that PsO is associated with several comorbidities such as psoriatic arthritis (PsA), metabolic syndrome and cardiovascular diseases. [6,7] As the number of individuals older than 65 years continues to rise, psoriasis and chronic diseases associated with psoriasis will likely increase in the geriatric population. Therefore, dermatologists will face a significant chailenge in psoriasis management in older adults. However, clinical studies of pspriasis in this specific age group have been rarely conducted. In fact, the elderly are more likely to have arthritis, bone and joint disorders, cancers, and other chronic disorders as sociated with a dramatic impact in quality of life.

Taking into consideration the comorbidities of a geriatric population of psoriatic patients, systemic therapies are often contraindicated. However, few studies and limited clinical trials evaluated the safety of conventional and biologic therapies in the treatment of elderly psoriatic patients sspecialiy in the long term. [8-11]. Among biologics, Infliximab (Remicade $($ ) is a chimeric haman-murine IgG1k monoclonal antibody, which binds with high affinity, avidity and specificity to TNF $\alpha$ approved by the EMA and FDA for the treatment of both PsO and PsA [12].This study aims to report our long-term experience on safety, efficacy and tolerance of infliximab in elderly patients under treatment with infliximab. 


\section{Material and Methods}

A retrospective review of the clinic database at the Department of Dermatology of the University of Rome Tor Vergata using the term "infliximab" was undertaken. Using this database-generated list, all charts were reviewed identifying psoriatic patients older than 65 , treated in the dar-care unit from 2002 to 2014.

The baseline characteristics of age, sex, psoriasis phenotype, onset of the disease, comorbidities, previous systemic treatments for psoriasis and any concurrent medications wers obtained.

According with the European and Italian guidelines all treated patients were unresponsive or contraindicated to at least two systemic conventional therapies. [13] Patients with infectious disease, active or latent tuberculosis (TBC), HIV neopiastic disease (in the previous 5 years), severe heart failure, or demyelinating disorders vere excluded.

Infliximab was administrated intravenousl at iveek 0, 2, 6 and then every 8 weeks. Clinical evaluation was assessed at each infusion using the validated psoriasis area and severity index (PASI).

At each infusion, physical eyamination, standard laboratory tests as well as measure of vital signs were assessed. The occurrence of adverse events (AEs) was also investigated and they were classified in mild, moderate and severe.

The afety anaiyses were performed in all subjects who received at least one dose of infliximab. Iaboratory data were recorded by visit descriptively and normal ranges pre-treatment versus post-treatment was provided.

2.1. Statistical analysis: Data from the clinical laboratory analyses were entered into a Windows-based database (Microsoft Excel 2007); all statistical analyses were expressed as means \pm standard deviation (SD). The significance of difference in the mean values obtained at 
T0, W12, 52, 104, and of treatment was assessed with an unpaired Student's t test (statistical significance set at $\mathrm{p} \leq 0.05)$.

\section{Results}

A total of 151 charts of patients treated with infliximab during the study period were analyzed. Twenty-seven/151 patients met the study criteria for inclusion. The range of the age was between 65-85 years old, average age $72 \pm 5.2$, female to male ratio was $1: 2$ and the mean age of onset was 43 years old \pm 17 . Fourteen patients suffered from plaque type psoriasis and 13 from psoriatic arthritis. Comorbidities included obesity, hypertension, gasirointestinal and cardiovascular diseases, diabetes mellitus, osteoporosis, hypercholesierclemia and thyroid dysfunction are reported in detailed in table 1. Three patients were also positive to TB Gold Quantiferon at the baseline and prophylaxis was prescribed according with the guidelines. [14]

The average of treatment duration was 39 nonths \pm 27 (range 1-100 months), with an average PASI score of $15.6 \pm 10.2$. Of those 27 patients, in $7 / 27$ infliximab was the second biologic therapy and for 1 patient the third biologic choice. Six patients combined methotrexate from 2 to 6 months at the dose 0 7.5.1.5 m/geekly. All patients affected by PsA underwent DMARDsbased therapy before the first infliximab infusion. Six patients were previously treated with methotrexate (7.5-15 mg/weekly) and acitretin (10-30 mg/day), 7 patients with Ciclosporin (3.5-5 $\mathrm{mg} / \mathrm{Kg}$ day and 3 patients with PUVA therapy. Seven patients had been already treated with another biologic drug: Adalimumab (2 patients), Etanercept (3 patients) and Efalizumab (2 paticits).

At week 12 a reduction in PASI score was observed in $80 \%$ of the patients: 4 patients achieved (PASI50), 3 patients between PASI75, 5 patients between PASI90 and 13 patients PASI 100

(Table 2). At week 12, 52, 104, and 208 the mean PASI was 2, 2.3, 1.9 and 1.8 respectively 
(Figure 1). The reduction in the mean PASI score was significant $(\mathrm{p}<0.001)$ from week 12 and maintained at week 208. Only 2 patients had a worsening of the disease.

Fifteen/27 discontinued the treatment for the following reasons: 6 patients for lack of efficacy (between week 38 and week 78), 2 continued the infusions in a different hospital, and 2 for adverse events. Adverse events are described in table 3 and those leading to disccntinuation included TBC reactivation $(\mathrm{n}=1$ at week 86), surgical operation $(\mathrm{n}=1$ at week 54$)$ and spondylodiscitis ( $\mathrm{n}=1$ at week 30$)$.

Infusions reactions were mild and led to treatment discontinuation in 2 patients at week 14 and week 46 (orticarioid reaction and uncontrolled arterial hypertension).

Twelve patients are currently under treatment ( $>100$ months therapies) showing efficacy and maintenance of PASI75 in the long-term ( $\mathrm{p}<0.001$, associated with a safety profile.

\section{Discussion}

In this article we report evidence of long-term safety and efficacy of infliximab in elderly psoriatic patients. To our knowledge, few clinical researches were focused in studying geriatric psoriatic patients under treatment with biologics in particular with infliximab. [8-11] A previous retrospective study perforned firoin our group evaluated the long-term efficacy and safety profile of subcutaneous etanercent and adalimumab, in the treatment of elderly patients affected by plaque-type Psc and PsA. [10] The study population of Esposito et al. [10] comprised total 89 patients: 51 patients treated with etanercept and 28 patients treated with adalimumab. The authors reported that the main comorbidities associated with psoriatic patients were PsA, cardiovascular conditions, and metabolic abnormalities. They showed that in elderly both treatments were effective and the proportion of patients achieving PASI50 was 91.80 and $82.14 \%$ at week 156 with etanercept and adalimumab treatment, respectively, while the proportion of patients achieving PASI75 was 83.61 and $71.43 \%$ at week 156 when treated with etanercept and adalimumab, respectively. Similarly to our observation, treatment adherence and safety profile 
were good. Similarly, Megna et al. [11] reported the efficacy and safety of ustekinumab in a group of 22 elderly patients with psoriasis over a 2-year period showing that PASI75 was reached by over $90 \%$ of patients at week 100 .

In our study we reported in 27 elderly patients under treatment with infliximab a rapia RASI score reduction and these results were maintained in the long-term in 12 patien without discontinuation. Infusion reactions were mild. Several studies have shown the eficacy and safety profile of infliximab in plaque-type psoriasis, PsA, pustular and erytredermic psoriasis as monotherapy or in combination with Methotrexate in children and adults. [15-17] In our experience, infliximab was safe in the long-term as monotherapy or in combination with Methotrexate. The safety profile should be a primary need especially in elderly patients in whom the comorbidities should be taken into consideration whin a treatment is proposed, for the higher risk of side effects and drug interactions. The irequent association with other major comorbidities requires efficacious treatment options that can be safely administered on a long-term period. Moreover, adherence to therapies is a primary determinant of treatment success and physicians, and nurses have-a key role to improve patient medication adherence in geriatric patients that need short hospitalization for inflixima infusions. A survey that asked which route of administration for anti-TNF therapy was preferred by patients with rheumatoid arthritis indicated a preference for IV adrinistration (that is, with infliximab) over a subcutanoeus regimen [18]. In this survey, factors for this preference included patients' general dislike of subcutanoeus injections, pain and irritation at the injection site, more frequent administration of the subcutanoeus -administered drug, difficulty in handling secure medication containers, and the clinical assistance attendant on iV administration. [18] In fact, in our experience IV dosing allows continuous dosage adjustments to be made, affording flexibility in matching patient needs at any given time during the infusion, helping to optimize overall treatment outcomes, appropriate monitoring and early diagnosis of comorbidities (i.e. blood pressure is continuously monitored during the infusions, 
blood exams are performed at each infusion). The latter could be related to the safety profile observed in our elderly population.

Even if in a small cohort of patients, our data suggested that infliximab is well tolerated, safe, ard effective in the long term in treating elderly patients affected by psoriasis or psoriatic anthritis despite common comorbidities occurring in an over-65 years old population. The TV thercpy was also associated with a high compliant profile and the hospitalization and the montitering of vital signs as well as the clinical visit assessed at any infusion can lead to early diagnosis of comorbidities.

\section{Expert opinion}

In elderly patients the chronic nature of the disease and the association with other major comorbidities requires efficacious treatment options that can be safely administered on a continuous long term basis. In contrast to subcutaneous drugs, the IV therapy allows a constant and continuous evaluation of patients comierbidities and possible adverse events by radiological exams, blood tests, and measurensent of vital parameters. The latter were taken at each infusion leading to early recognition of undiagnosed cardiovascular diseases (i.e. hypertension), pneumological conditions (i.e. COPD), infections or even cancers. However, since elderly minorities have low clinical trial participation in psoriatic population, our limited experience suggests that infliximab is safe, effective and associated with a high compliance in the long term. Finally, effectiveness and safety outcomes appear to be comparable between intravenous and subculaneous anti-TNF-alpha agents in elderly patients with PsO and PsA.

\section{Acknowledge:}

Special thanks should be given to Prof. Sergio Chimenti, our research project supervisor for his professional guidance, valuable support and for his useful and constructive recommendations . 


\section{Funding}

This paper was not funded

\section{Declaration of Interest}

The authors have no relevant affiliations or financial involvement with any organization oi entity with a financial interest in or financial conflict with the subject matter or materials discussed in the manuscript. This includes employment, consultancies, honoraria, stock ownership or options, expert testimony, grants or patents received or pending, or royalties.

\section{References:}

Papers of special note have been highlighted as:

* of interest

** of considerable interest

1. Christophers E. Psoriasis-epidemiology and clinical spectrum. Clin Exp Dermatol. 2001; $26: 314-320$.

2. Henseler T, Christophers E. F'soriasis of early and late onset: characterization of two types of psoriasis vulgaris. J/Am Acad Dermatol.1985;13:450-456.

3. Bell LM1, Sediack R, Beard CM, et al. Incidence of psoriasis in Rochester, Minn, 19801983. Arch Dermatol. 1991;127(8):1184-1187.

4. Kon $\mathrm{HH}^{1}$, Kwon IH, Youn JIClinical study of psoriasis occurring over the age of 60 years: is elderly-onset psoriasis a distinct subtype? Int J Dermatol. 2012;51(1):53-58.

5. Farber EM, Nall ML. The natural history of psoriasis in 5,600 patients. Dermatologica. 1974;148(1):1-18.

6. Zachariae H. Prevalence of joint disease in patients with psoriasis: implications for therapy. Am J Clin Dermatol. 2003;4(7):441-447. 
7. Davidovici BB, Sattar N, Prinz J, et al. Psoriasis and systemic inflammatory diseases: potential mechanistic links between skin disease and co-morbid conditions. J Invest Dermatol. 2010;130(7):1785-1796.

8. Balato N, Patruno C, Napolitano M, Patrì A, Ayala F, Scarpa R. Managing moderate-tosevere psoriasis in the elderly. Drugs Aging. 2014;31(4):233-238.

9. Migliore A, Bizzi E, Laganà B, et al. The safety of anti-TNF agents in the elderly. Int $J$ Immunopathol Pharmacol. 2009;22(2):415-426.

10. Esposito M, Giunta A, Mazzotta A, et al. Efficacy and Safety of Subcutaneous AntiTumor Necrosis Factor-Alpha Agents, Etanercept and Adalimumab, in Elderly Patients Affected by Psoriasis and Psoriatic Arthritis: An Observational Long-Term Study. Dermatology. 2012 Dermatology. 2012;225(4):312-319.

** The study reported long-term efficacy and sarety profile of subcutaneous etanercept and adalimumab, in the treatment of 89 elderly patients affected by plaque-type Pso and PsA.

11. Megna M, Napolitano M, Balato N, et al. Efficacy and safety of ustekinumab in a group of 22 elderl patients with psoriasis over a 2-year period. Clin Exp Dermatol. $2016 ; 41(5) ; 564-565$

** The study reported the efficacy and safety of ustekinumab in a group of 22 elderly patients with psoriasis over a 2-year period showing that PASI75 was reached by over $90 \%$ of patients at week 100.

12. Saraceno R, Saggini A, Pietroleonardo L, Chimenti S. Infliximab in the treatment of plaque type psoriasis. Clin Cosmet Investig Dermatol. 2009;2:27-37.

13. Pathirana D, Ormerod AD, Saiag P, et al. European S3-guidelines on the systemic treatment of psoriasis vulgaris. J Eur Acad Dermatol Venereol. 2009;23 Suppl 2:1-70. 
14. British Thoracic Society Standards of Care Committee. BTS recommendations for assessing risk and for managing Mycobacterium tuberculosis infection and disease in patients due to start anti-TNF-alpha treatment. Thorax. 2005;60:800-805

15. Smolen JS, Emery P. Infliximab: 12 years of experience. Arthritis Res Ther. $2011 ; 13$ Suppl 1:S2. 2

16. Baranauskaite A, Raffayová H, Kungurov NV, et al. RESPOND investigators; InI1 ximab plus methotrexate is superior to methotrexate alone in the treatment of psoriatic arthritis in methotrexate-naive patients: the RESPOND study; Ann Rhein Dis. 2012;71:541-548

17. Chaudhari U, Romano P, Mulcahy LD, et al. Efficacy and safety of Infliximab monotherapy for plaque- type psoriasis: a randomised trial. Lancet. 2001; 357: 18421847.

18. Viller F, Guillemin F, Briancon S, et ai complance to drug treatment of patients with rheumatoid arthritis: a 3 year longitudinal study. J Rheumatol. 1999, 26:2114-2122.

* Survey showing that patients wuli rheumatoid arthritis indicated a preference for IV administration over a subcutanoeus regimen. 
Table 1. Comorbidities

\begin{tabular}{|l|l|}
\hline Co-morbidities & \\
\hline Arterial hypertension & 10 \\
\hline Cardiovascular disease & 5 \\
\hline Diverticulum & 4 \\
\hline COPD & 4 \\
\hline Gastrointestinal disease & 4 \\
\hline Monoclonal Gammopathy & 4 \\
\hline TB Gold Quantiferon + & 3 \\
\hline Artrosis & 3 \\
\hline Diabetes Mellitus type II & 2 \\
\hline Hyperlipidemia/Hypercholesterolemia & 1 \\
\hline Prostate Hypertrophy & 1 \\
\hline Cerebrovascular ischemia & 1 \\
\hline Hemorrhoids & 1 \\
\hline Glaucomas bilateral & 1 \\
\hline Depression syndrome & 1 \\
\hline Anxiety & 1 \\
\hline
\end{tabular}

Table 2. per cent of reduction in PASI score at week 12

\begin{tabular}{|l|l|}
27 Patients & 4 \\
\hline Reduction PASI $\geq 50 \%<75 \%$ & 3 \\
\hline Reduction PASI $\geq 75 \%<90 \%$ & 5 \\
\hline Reduction PASI $\geq 90 \%$ & 13 \\
\hline Increase PASI & 2 \\
\hline
\end{tabular}


Table 3. Adverse events during the treatment

\begin{tabular}{|ll|}
\hline ADVERSE EVENTS \\
Flu like syndrome & 12 \\
\hline Hypertension & 4 \\
\hline Candidiasis & 5 \\
\hline Cystitis & 2 \\
\hline Herpes Zoster & 2 \\
\hline Basal cell carcinoma & 2 \\
\hline Hyperlipidemia & 1 \\
\hline Diarrhea & 1 \\
\hline Lithiasis Uterus bladder & 1 \\
\hline Perianal fistula & 1 \\
\hline Headache & 1 \\
\hline Irregular profile gamma & 1 \\
\hline
\end{tabular}

Figure 1: The graph shows the mean PAST score at baseline, week 12, 52, 104 and 208 of 12 patients that were treated with infliximab in the long term without discontinuation.

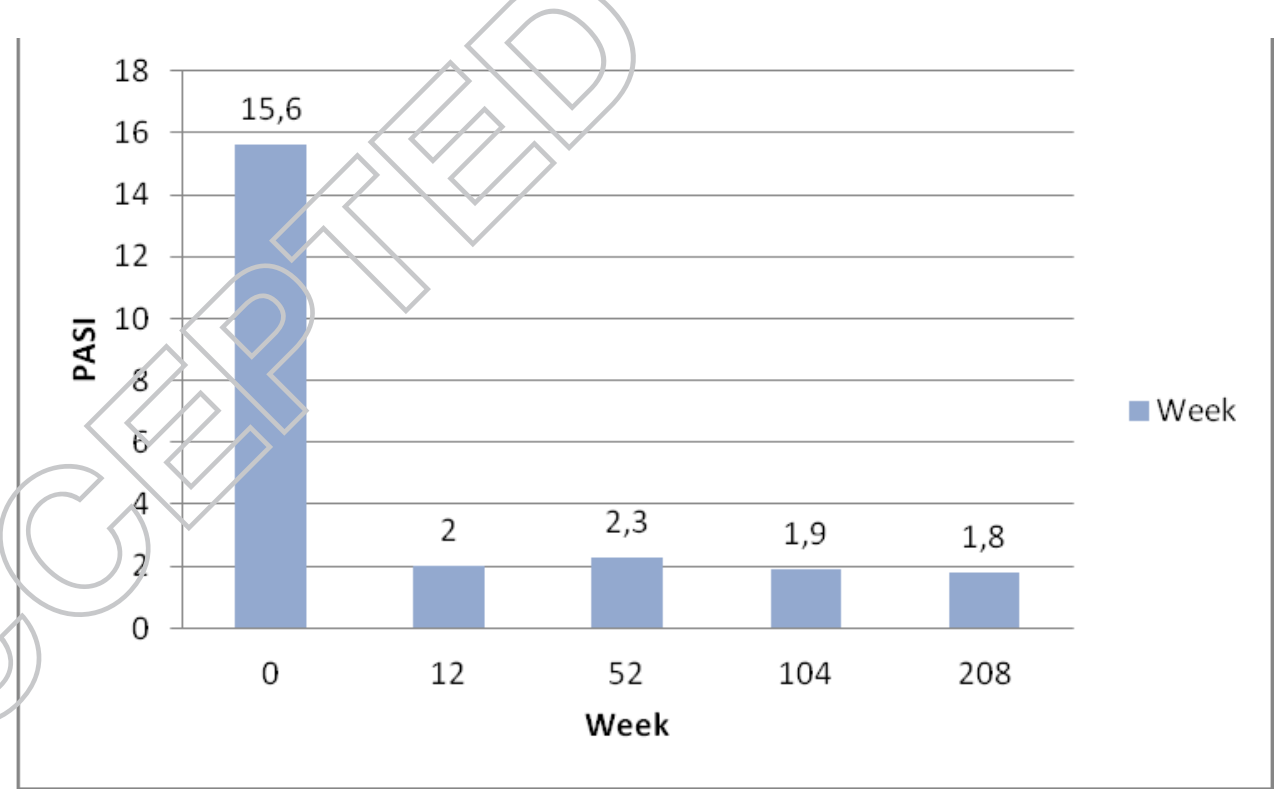

